\title{
DETERMINING PCB TRACE CAPABILITY AND FUSING, USED IN SWITCH MODE POWER SUPPLIES, BASED ON MODELING AND SIMULATION WITH THE FINITE ELEMENT METHOD
}

\author{
Borislav DIMITROV*, Andrew CRUDEN ${ }^{* *}$, Suleiman SHARKH** \\ Faculty of Engineering and the Environment, University of Southampton, Southampton, UK, \\ E-mail: *B.H.Dimitrov@soton.ac.uk, ${ }^{* *}$ A.J.Cruden@soton.ac.uk, ${ }^{* * *}$ S.M.Abu-Sharkh@soton.ac.uk
}

\begin{abstract}
$P C B$ fuses are used widely in small power and small size electronic devices such as switch mode power supplies, chargers etc. They offer small size and low cost but their dependency of the track's geometry make them imprecise. The aim of this research is to show an approach for improving the design procedure, leading to improved parameters and operation of the fuse. The suggested design is based on modeling with finite element method and numerical simulation. Experimental results validating this work are presented.
\end{abstract}

Keyword: PCB fuse, switch mode power supply, electronic device, finite element method, simulation, experiments

\section{INTRODUCTION}

Modern PCB fuses have their application in contemporary low power electronic devices such as switch mode power supplies for battery chargers, LED lamps, different mobile applications etc. Their major advantage is compactness i.e. small mass and size, and lower cost, compared to ordinary fuses with fusible plugs. The PCB fuses are applicable only in unserviceable units with relatively small power and consequently small size. These characteristics helped designers to reduce entire devices' size and cost. In addition, these types of fuses have a significant disadvantage - they are not precise enough, because the accuracy depends on the geometrical characteristics of the tracks. The experimental results show that when they blow under short circuit this often causes the switching-off of the central circuit breaker or fuse, which is an unacceptable event. This problem has been mentioned with several electronic devices available on the market. Experiments conducted with ten identical boards (switch mode power supply for battery charging, offered from the same manufacturer) showed that four of them caused switching of the central switch before the PCB fuse.

Numerous literature sources are focused on PCB trace current and heat ability and showed results in a different directions. Some of them are focused on application of the numerical methods in the design procedure of the PCB trace. Papers $[1,2,3]$ show research of the PCB track capability and application of contemporary mathematical apparatus. Paper [4] used modelling with numerical methods in order to determine their temperature under steady state conditions. A lot of research has been conducted regarding general issues as traces current abilities, calculation of the losses, high frequency ability and noise on the PCB boards etc. $[5,6,7,8]$. The design procedure is given in $[9,10,11]$ and design standards [12] is describes in detail in $[3,13]$. The use of the traces as fuses is given in [14] where the modeling procedure and the final experiments with them as part of the electronic device are not presented.
The aim of this research is to show a new approach, leading to improved precision of the fuse and eventually to improve the design procedure of the entire electronic device. This approach is based on modeling with numerical methods (Finite Element Method FEM) which are included in established analytical procedures, in order to complement and improve them. The result should give a more correct definition of the mass and geometric characteristic of the tracks, used as PCB fuse.

\section{ANALYSIS}

Generally, ordinary fuses used in switch mode power supplies are selected according to their let-through current, or $\mathrm{I}^{2} \mathrm{t}$ rating. This characteristic is provided from manufacturers in graphical and numerical manners, which make their selection methodology easy and strongly defined. Working with PCB fuses still requires a lot of experimental activity, design changing in order to alter the characteristics of the fuses, which are resources consumable.

The electrical circuit presented in fig.1, shows the connection between the circuit breaker, as part of the electrical installation, and electronic device protected with a PCB fuse. The major requirement on this schematic is: short circuit in the electronic device should cause the blowing of the PCB fuse and not the operation of the circuit breaker.

Several different examples of PCB fuses are presented in Fig. 2. The experiments showed in part 3 are conducted with the same boards.

The design of the fuses with fusible plug is based on an analytical procedure, with certain assumptions and mathematical analysis. If the current through the plug (trace) is over three times larger than nominal current then all the heat energy is used to heat the plug i.e. the process is adiabatic. The dependency between the time $\left(t_{m}\right)$ for reaching the melting temperature, the cross section of the plug and its material is given from the equation: 
$\mathrm{t}_{\mathrm{m}}=\mathrm{K}^{\prime} \frac{\mathrm{A}^{2}}{\mathrm{I}_{\mathrm{n}}^{2}}=\frac{\mathrm{K}^{\prime}}{\mathrm{J}_{\mathrm{n}}^{2}}$

where: $\mathrm{K}^{\prime}$ is a constant, depending on the material, for cooper $80000 \mathrm{I}^{2} . \mathrm{sec} / \mathrm{mm}^{4} ; \mathrm{A}$ is the cross section $\left(\mathrm{m}^{2}\right)$; $I_{n}$ is the current $(A) ; J_{n}$ is the current density $\left(A / \mathrm{m}^{2}\right)$.

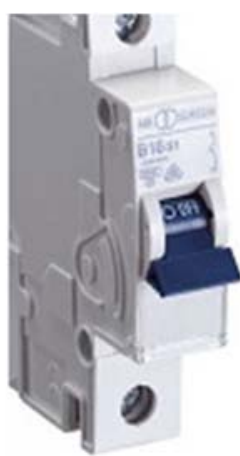

Circuit breaker
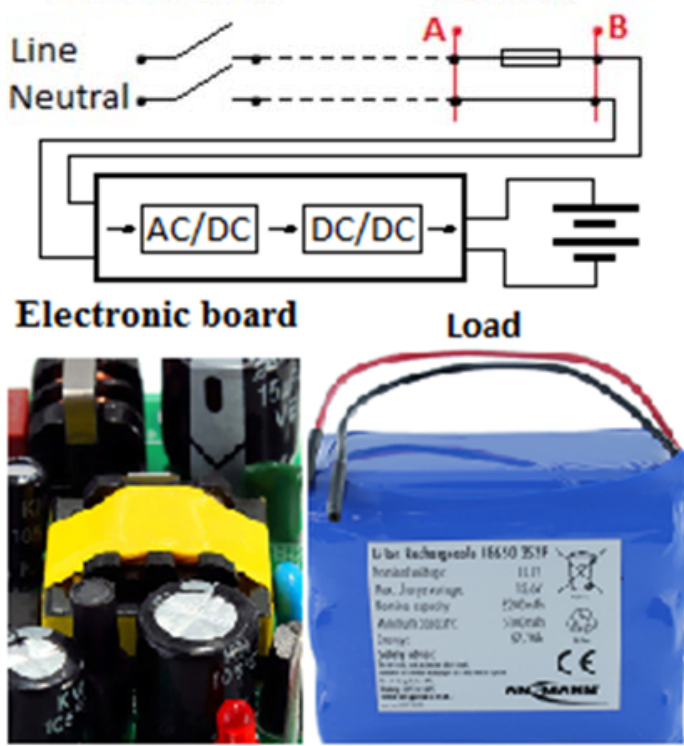

Fig. 1 PCB fuse as part of electrical circuit. Points A and B control points before and after the PCB fuse.

After time $t_{m}$ i.e. reaching the melting temperature, additional energy is necessary to change the state of the material from a solid to a liquid. This energy is equal to the latent heat capacity of the material. The time of this phase $\left(t_{p c}\right)$ is given by the equation:

$\mathrm{t}_{\mathrm{pc}}=\frac{\gamma \cdot \mathrm{T}_{\mathrm{L}}}{\rho_{\mathrm{l}}-\rho_{\mathrm{m}}} \ln \frac{\rho_{\mathrm{l}}}{\rho_{\mathrm{m}}} \frac{\mathrm{A}^{2}}{\mathrm{I}_{\mathrm{n}}^{2}}=\mathrm{K}^{\prime \prime} \frac{\mathrm{A}^{2}}{\mathrm{I}_{\mathrm{n}}^{2}}$

where: $\rho_{\mathrm{m}}$ is the specific resistance on the melting temperature; $\rho_{\mathrm{l}}$ is the resistance of the liquid metal; $\gamma$ is density; $\mathrm{T}_{\mathrm{L}}$ is the latent heat; $\mathrm{K}^{\prime \prime}$ is a constant, depending on the material, for cooper $11600 \mathrm{I}^{2}$. sec $/ \mathrm{mm}^{4}$.

The sum of the equations (1) and (2) determine the transient time of the switch-off process of the fuse $\left(\mathrm{t}_{\text {fuse }}\right)$. More precisely this sum must contain the time of the electrical ark extinguishing $\left(\mathrm{t}_{\text {arc }}\right)$ also, or:

$\mathrm{t}_{\text {fuse }}=\mathrm{t}_{\mathrm{m}}+\mathrm{t}_{\mathrm{pc}}+\mathrm{t}_{\mathrm{arc}}$
The last component is often described experimentally, but for practical purposes the next equation is applicable:

$\mathrm{t}_{\text {fuse }}=\left(\mathrm{K}^{\prime}+\frac{\mathrm{K}^{\prime \prime}}{\mathrm{c}}\right) \times \frac{\mathrm{A}^{2}}{\mathrm{I}_{\mathrm{n}}^{2}} \times \mathrm{k}_{0}$

where: $\mathrm{c}$ is the experimental coefficient showing the destruction of the fuse, commonly $\mathrm{c}=3 ; \mathrm{k}_{0}$ is the coefficient considering the time $\mathrm{t}_{\mathrm{arc}}$, commonly $\mathrm{k}_{0}=$ $1.2 \div 1.3 ; \mathrm{K}^{\prime}$ is a constant, depending on the material, for cooper $80000 \mathrm{I}^{2} \cdot \mathrm{sec} / \mathrm{mm}^{4} ; \mathrm{K}^{\prime \prime}$ is a constant, depending on the material, for cooper $11600 \mathrm{I}^{2}$. sec/ $\mathrm{mm}^{4}$;

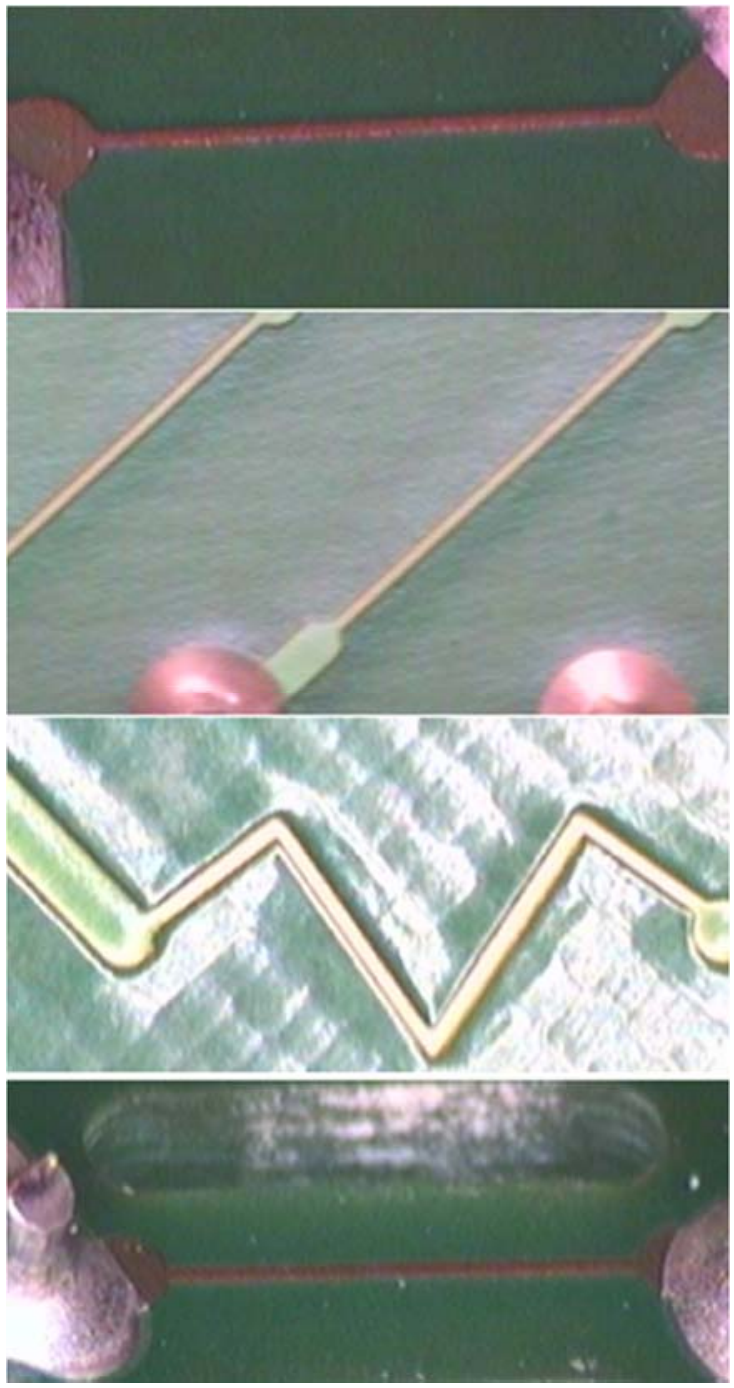

Fig. 2 Experimental PCB fuses

The analytical design procedure is based on the determination of the traces cross-section as a functional dependency of temperature, according to the widely used standard IPC-2221 [12]. Fig. 3 shows the methodology of estimation of the temperature rise due to electrical current. This process has two general steps, following the dashed arrows in Fig. 3: determine the cross-section according to the thickness of the trace; determine the temperature rise and maximum permitted current.

The same analytical design can be based on two equations, specified in $[3,12,14]$ with the format: 
$\mathrm{I}=\mathrm{k} \cdot \Delta \mathrm{T}^{\beta 1} \cdot \mathrm{A}^{\beta 2}$

W here: I is the current (amps); $\Delta \mathrm{T}$ is the change in the temperature above ambient $\left(\mathrm{C}^{\mathrm{O}}\right)$; $\mathrm{A}$ is the cross section area (square mills); $\mathrm{k}, \beta 1, \beta 2$ are coefficients.

According to the IPC standard equation (5) has the parameters:

$\mathrm{I}=0.065 \times \Delta \mathrm{T}^{0.43} \times \mathrm{A}^{0.68}$

and according to [3], the same equation is specified as:

$\mathrm{I}=0.040 \times \Delta \mathrm{T}^{0.45} \times \mathrm{A}^{0.69}$

Although the standard IPC-2221 allows a fast and straightforward design, the data shows that it can be used only for the general design of the PCB trace. This standard is not applicable for the design of fuses, because their melting temperatures are not available.

The results of the presented equations and analytical methodology of design have to be compared and corrected according to results from FEM procedure in the context of the design of the PCB fuses.
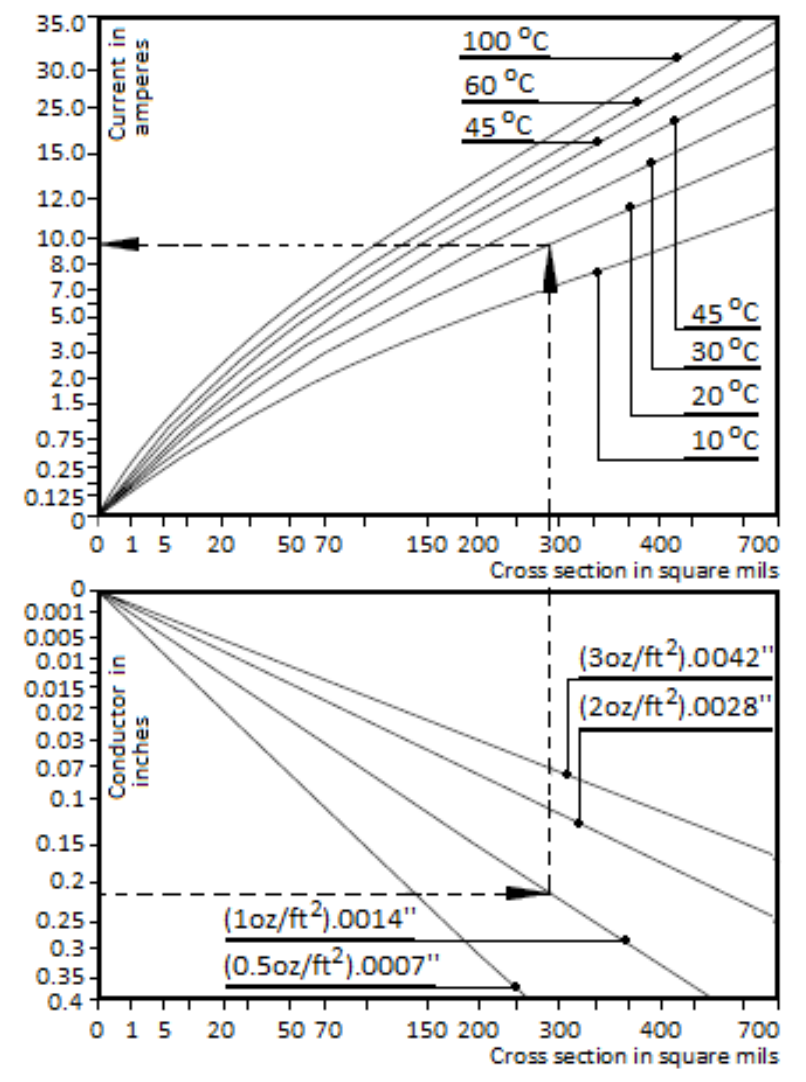

Fig. 3 Nomograph from the standard IPC-2221

\section{NUMERICAL MODELING OF THE PCB FUSE WITH FINITE ELEMENT METHOD}

Two models, showing the basic work modes, short circuit and normal conductivity mode are prepared. The simulation procedure is realised with a specialised product
[15] and is based on a multiphysical model including Heat transfer and Joule heating modules. The models work with different time constants and this requires consideration of the boundary condition. Both models are based on direct resistance heating theory.

Due to the small time constant of the short circuit mode, the heat transfer between the PCB fuse, the environment and the board can be neglected. With this assumption, thermal transfer with convection and radiation are excluded from the model. The thermal transfer is only through conductivity in the body of the fuse. Such an adiabatic process requires thermal insulation around the fuse.

The heat transfer in solids steady-state problem is described with the equation:

$\rho C_{p} \frac{\partial T}{\partial t}+\rho C_{p} u . \nabla T+\nabla \cdot q=Q$

$\mathrm{q}=-\mathrm{k} \cdot \nabla \mathrm{T}$

Where: $\rho$ is the density $(\mathrm{kg} / \mathrm{m} 3) ; C_{p}$ is the heat capacity $(\mathrm{J} /(\mathrm{kg} . \mathrm{K})) ; \mathrm{T}$ is the temperature $(\mathrm{K}) ; \mathrm{u}$ is the velocity field vector $(\mathrm{m} / \mathrm{s})$; $\mathrm{Q}$ is the heat source $(\mathrm{W} / \mathrm{m} 3) ; \mathrm{q}$ is the heat flux vector $(\mathrm{W} / \mathrm{m} 2) ; \mathrm{k}$ is the conductivity $(\mathrm{W} /(\mathrm{m} . \mathrm{K}))$.

The boundary condition for thermal insulation is described as:

$-\mathrm{n} \cdot \mathrm{q}=0$

Where: $\mathrm{n}$ is the vector potential.

If the model represents the normal continuous mode of operation, the last condition should be replaced by convection and radiation between the top surface of the fuse and the environment and conduction between the bottom surface of the fuse and the board. In this case the process of heat transfer in the complete system (fuse track - board - ambient environment) is described from equation (8) with the equation:

$$
\begin{aligned}
& \rho . C_{P}\left(\frac{\partial T}{\partial t}+(u . \nabla) T\right)=-(\nabla . q)+\tau: \\
& S-\left.\frac{T}{\rho} \frac{\partial \rho}{\partial T}\right|_{P}\left(\frac{\partial p}{\partial t}+(u . \nabla) p\right)+Q
\end{aligned}
$$

Where $S=\frac{1}{2}\left(\nabla u+(\nabla u)^{T}\right)$ is the strain-rate tensor $(1 / \mathrm{s}), \tau$ is the viscous stress tensor $(\mathrm{Pa})$;

In the models developed from the equation (11) the stationary mode is reduced to:

$\rho \mathrm{C}_{\mathrm{p}} \frac{\partial \mathrm{T}}{\partial \mathrm{t}}+\nabla \cdot(-\mathrm{k} \cdot \nabla \mathrm{T})=\mathrm{Q}$

The necessary border condition is heat flow and radiant heat transfer between surfaces:

$$
\begin{aligned}
& -n \cdot(-k \nabla T)=q_{0}+h\left(T_{\mathrm{inf}}-T\right)+\varepsilon\left(G-\sigma \cdot T^{4}\right) \\
& (1-\varepsilon) \cdot G=J_{0}-\varepsilon \sigma T^{4}
\end{aligned}
$$


Where $\mathrm{n}$ is a vector normal to the corresponding surface, $G$, J are the incoming and emitted flux respectively.

The heat transfer between surface and environment is described by the equation:

$$
G=\sigma \cdot T_{a m b}^{4}
$$

Thus the heat flux obtained is given as:

$$
q=\varepsilon \cdot \sigma \cdot\left(T_{a m b}^{4}-T^{4}\right)
$$

Where: $\varepsilon$ is blackness coefficient, $\mathrm{T}_{\mathrm{amb}}$ is ambient temperature $[\mathrm{K}], \sigma$ is the Stefan-Boltzmann constant.

The border condition used is heat flow through the respective surface, identified as follows:

$$
q=-k \nabla T+\rho \cdot C_{p} u T
$$

The thermal model of the PCB fuse includes the phase change process during the melting time of the conducting trace. The model heat transfer with phase change is based on equations:

$\rho=\theta \rho_{\text {phase } 1}+(1-\theta) \rho_{\text {phase } 2} ; \rho H=\theta \rho_{\text {phase } 1} \mathrm{H}_{\text {phase } 1}+$ $+(1-\theta) \rho_{\text {phase } 2} \mathrm{H}_{\text {phase } 2}$

Where $\rho$ is the specific capacity, $H$ is the specific enthalpy, indices phase 1 and phase 2 indicate the fuse in phase 1 (before has reached the melting temperature) and in phase 2 (during the melting temperature) respectively, $\theta$ is the temperature difference.

The specific capacity $C_{p}$ :

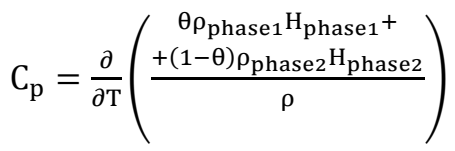

Eventually, the latent heat capacity $\mathrm{C}_{\mathrm{L}}$ is:

$C_{L}(T)=\left(H_{\text {phase } 2}-H_{\text {phase } 2}\right) \frac{d \alpha_{m}}{d T}$

where $\alpha_{\mathrm{m}}$ is the mass function:

$\alpha_{\mathrm{m}}=\frac{1}{2} \frac{\theta_{2} \rho_{\text {phase } 2}-\theta_{1} \rho_{\text {phase } 1}}{\rho}$

Here, the transformation occurs in a temperature interval between $\mathrm{T}_{\mathrm{pc}}-\Delta \mathrm{T} / 2$ and $\mathrm{T}_{\mathrm{pc}}+\Delta \mathrm{T} / 2$, where $\mathrm{T}_{\mathrm{pc}}$ is the phase change temperature. The phase changing process is described by a smoothed function $(\theta)$, representing the fraction of phase before transition.

The Joule heating model describes the heating of the electrical conductor from the electrical current passing through it due to the Joule losses. The equation that describes the dependency between the conductivity of the material, in this case copper PCB track, and temperature is:

$$
\sigma=\frac{1}{\rho_{0}\left(1+\alpha\left(T-T_{0}\right)\right)}
$$

Where: $\rho_{0}(\Omega . \mathrm{m})$ is the resistivity; $\alpha\left(\frac{1}{\mathrm{~K}}\right)$ is the resistivity temperature coefficient; $\mathrm{T}$ and $\mathrm{T}_{0}(\mathrm{~K})$ are the current temperature and the reference temperature.

The external current density J appears in Ohm's law and is described by the following equations:

$\nabla . J=Q_{j}$

$\mathrm{J}=\sigma \cdot \mathrm{E}+\frac{\partial \mathrm{D}}{\partial \mathrm{t}}+\mathrm{J}_{\mathrm{e}}$

$\mathrm{E}=-\nabla \mathrm{V}$

Eventually, the current conservation is:

$\mathrm{J}=\left(\sigma+\varepsilon_{\mathrm{o}} \varepsilon_{\mathrm{r}} \frac{\partial}{\partial \mathrm{t}}\right) \cdot \mathrm{E}+\mathrm{J}_{\mathrm{e}}$

Where: $\mathrm{J}_{\mathrm{e}}$ is external current density $\left(\frac{\mathrm{A}}{\mathrm{m}^{2}}\right) ; \varepsilon_{0}, \varepsilon_{\mathrm{r}}$ are the permittivity of the free space and relative permittivity respectively; $Q_{J}\left(\frac{A}{m^{2}}\right)$ is current source, described by equation:

$Q_{j}=n \cdot\left(J_{1}-J_{2}\right)$

The electric isolation boundary condition means that no electric current flows through the boundary i.e. leakage between the fuse track and PCB is neglected. The equation is:

n. $\mathrm{J}=0$

The materials used for the model are fiberglass (PCB board), copper (fuse track) and air (surrounding environment). The thermal and electrical parameters of the copper are shown in table 1. The two other materials, fiberglass and air, have only thermal characteristics shown respectively in Table 2 and Table 3.

The result of the simulation procedure is shown on figures 4 and 5, respectively with nominal and short circuit current.

The last model, based on short circuit, does not require the environment and the PCB board to be included in it, because the time is too short for any thermal conducting in the entire system. This means that only fuse track needs to be modelled. This approach saves computer resources, calculation time and consequently reduces the time for the design.

Fig. 6 shows zig-zag trace fuses, modelled in short circuit mode. The same geometry is shown on Fig. 2 and is widely used in electronic devices, as it gives an option a bigger length to be allocated on a limited place. The simulation shows the temperature difference between the angle and the linear part of the trace. It can be expected that the melting process will begin from the linear part, which shows the similar thermal operation as linear geometry. 
Table 1 Electrical and thermal parameters of the cooper, used for the fuse.

\begin{tabular}{lll}
\hline \multicolumn{1}{c}{ Electrical conductivity } & $\mathbf{5 . 9 E 7}$ & $\mathbf{( S / m )}$ \\
\hline Heat capacity & 385 & $(\mathrm{~J} /(\mathrm{kg} \cdot \mathrm{K}))$ \\
Heat latent capacity & 207 & $(\mathrm{~J} /(\mathrm{kg} \cdot \mathrm{K}))$ \\
Density & 8700 & $\left(\mathrm{~kg} / \mathrm{m}^{3}\right)$ \\
Thermal conductivity & 400 & $(\mathrm{~W} /(\mathrm{m} . \mathrm{K}))$ \\
Reference resistivity & $1.72 \mathrm{E}-8$ & $(\Omega \cdot \mathrm{m})$ \\
Resistivity temp. coefficient & 0.0039 & $(1 / \mathrm{K})$ \\
Reference temperature & 298 & $(\mathrm{~K})$ \\
Melting temperature & 1358 & $(\mathrm{~K})$ \\
\hline
\end{tabular}

Table 2 Thermal parameters of the fiberglass, used for the board.

\begin{tabular}{lll}
\hline \multicolumn{1}{c}{ Thermal conductivity } & $\mathbf{0 . 0 4}$ & $(\boldsymbol{W} /(\boldsymbol{m} \cdot \boldsymbol{K}))$ \\
\hline Heat capacity & 400 & $(\mathrm{~J} /(\mathrm{kg} \cdot \mathrm{K}))$ \\
Density & 100 & $\left(\mathrm{~kg} / \mathrm{m}^{3}\right)$ \\
Electrical conductivity & 0 & $(\mathrm{~S} / \mathrm{m})$ \\
\hline
\end{tabular}

Table 3 Thermal parameters of the surrounding air at $20^{\circ} \mathrm{C}$.

\begin{tabular}{lll}
\hline Thermal conductivity & $\mathbf{0 . 0 2 5 7}$ & $(\boldsymbol{W} /(\boldsymbol{m} \cdot \boldsymbol{K}))$ \\
\hline Heat capacity & 1.005 & $(\mathrm{~J} /(\mathrm{kg} \cdot \mathrm{K}))$ \\
Density & 1.205 & $\left(\mathrm{~kg} / \mathrm{m}^{3}\right)$ \\
Kinematic viscosity & $15.11 \times 10^{-6}$ & $\left(\mathrm{~m}^{2} / \mathrm{s}\right)$ \\
Expansion coefficient & $3.43 \times 10^{-3}$ & $(1 / \mathrm{K})$ \\
Prandtl's Number & 0.713 & \\
\hline
\end{tabular}

Fig. 7 shows the phase changing process during the entire melting time. Generally, that time depends on two parameters: the heat latent capacity (Table 1) and the geometric characteristic of the fuse. This simulation shows how the phase changing time can be altered during the design procedure with changing the thinness, the length and the width of the fuse. Here, the first thinness $(0.6 \mathrm{~mm})$ is bigger than the second $(0.5 \mathrm{~mm})$ and the third $(0.4 \mathrm{~mm})$. Such reducing of the overall volume reduces the phase change time.

It must be considered that the time for the phase change process is not equal to the entire switched-off time of the fuse. After this process consequently start two processes of evaporating and arc extinguish. This feature requires a series of conducting conformation experiments.

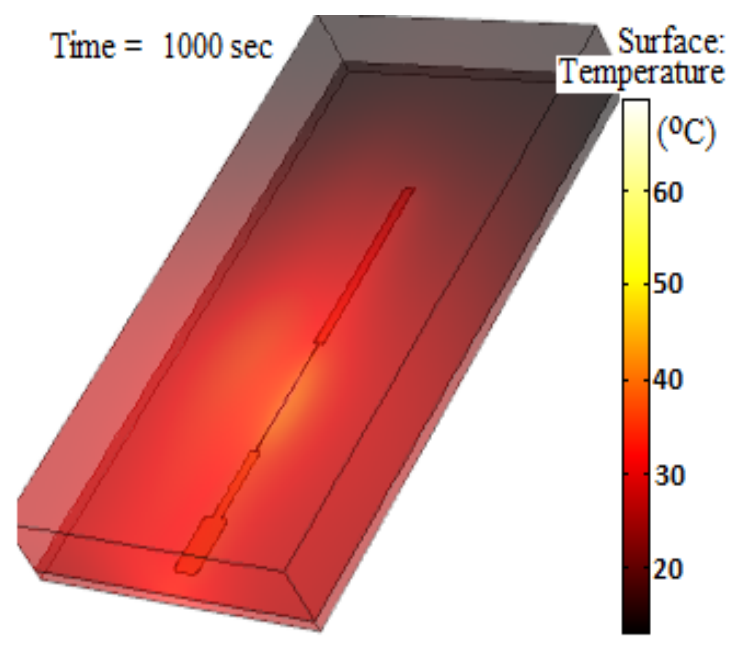

Fig. 4 Thermal field as result of FEM simulation procedure. Established of the process with nominal current through the PCB fuse track.

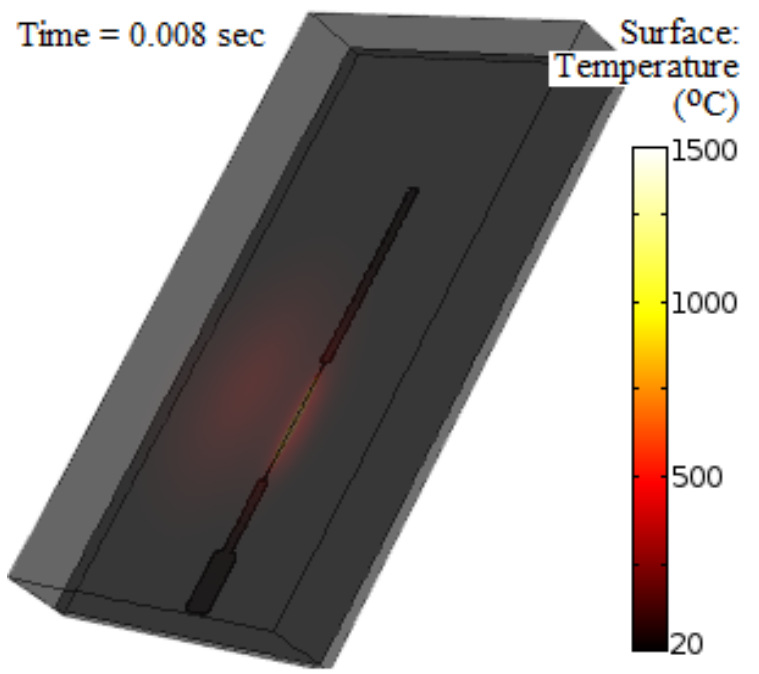

Fig. 5 Thermal field as result of FEM simulation procedure. Temperature with short circuit current.

\section{EXPERIMENTAL RESULTS}

Experimental results are provided according to the schematic on Fig. 1 with 10 different PCB fuses, produced according to the shown FEM models - linear, zigzag and spiral shapes. The major requirements are:

- During a short circuit of the electronic device only the PCB fuse should blow.

- The circuit breaker must not switched-off and the other loads powered with it must not be affected.

- The current breaker is rated of $16 \mathrm{~A}$ class $\mathrm{C}$.

- The PCB fuse must not blow during the transient switch-on process of the electronic device due to inrush current. 
The major problem is presented in Fig. 8, which is found with a battery charger available on the market. Curve 1 and 2 are $A C$ voltage respectively before (point A, Fig. 1) and after (point B) the PCB fuse. Curve 3 is the current through the entire schematic: circuit breaker, fuse and electronic device. In the moment of short circuit, the fuse blows together with the shutting down of the circuit breaker. This is depicted in curve 1 which also stops after the short circuit.

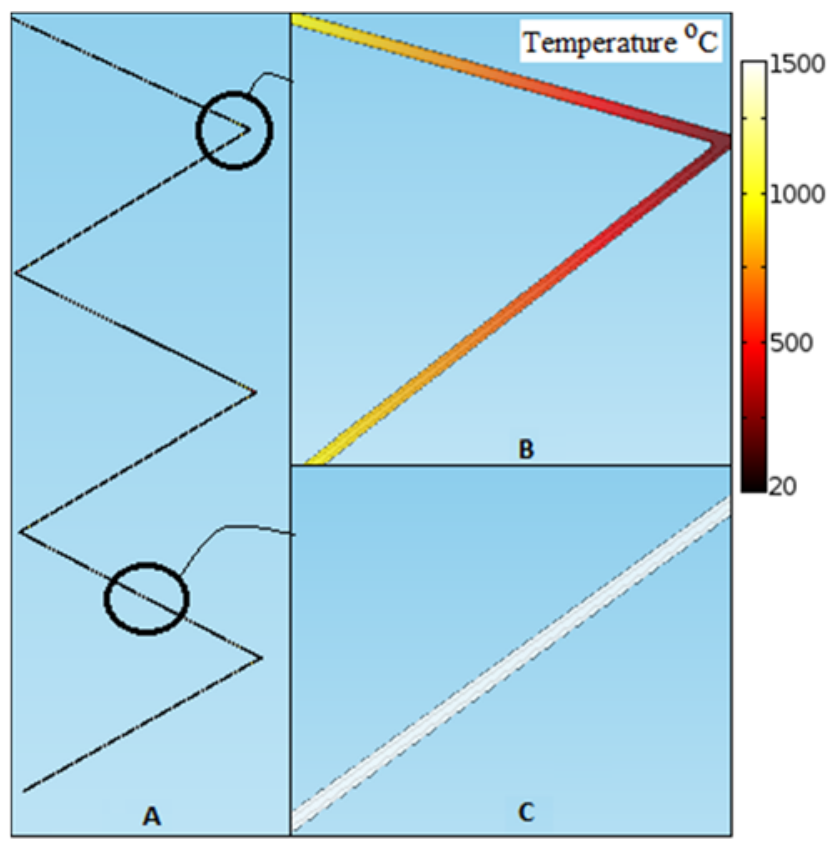

Fig. 6 A: Zig-zag PCB fuse, FEM simulation procedure; B: temperature distribution on the angle; $\mathrm{C}$ : temperature distribution on the linear part. The color temperature line is the same as Fig. 4.

The first correction of the design is shown in Fig. 9. For these experiments 10 different PCB fuses are used as well as numerical and physical models, with different geometrical characteristics: thickness between 0.2 and 1.1 $\mathrm{mm}$ and length of $20 \mathrm{~mm}$. Fig. 8 shows that the voltage is continued after the short circuit but only for a half period, which is an unsuccessful result.

This problem is solved with several geometrical corrections of the PCB fuse, based on analytical calculations and modeling with FEM. The result is shown on Fig.10. In the moment of short circuit only the fuse interrupts the current and disconnects the circuit - curve 2 . This event does not affect the work of the circuit breaker and curve 1 is not interrupted.

Eventually, the design algorithm is shown in Fig. 11. The geometrical parameters of the PCB fuse are corrected according to the interaction procedure, based on presented FEM simulations and experiments.
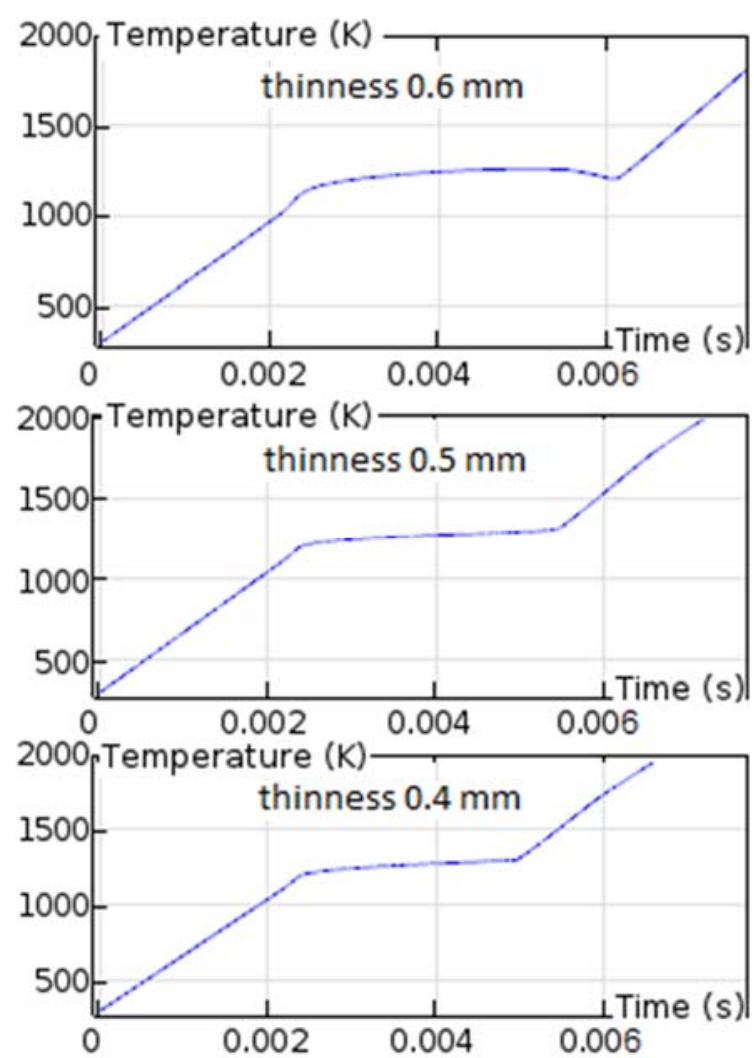

Fig. 7 A melting process of the PCB fuse during its short circuit. The results are based on a FEM model.

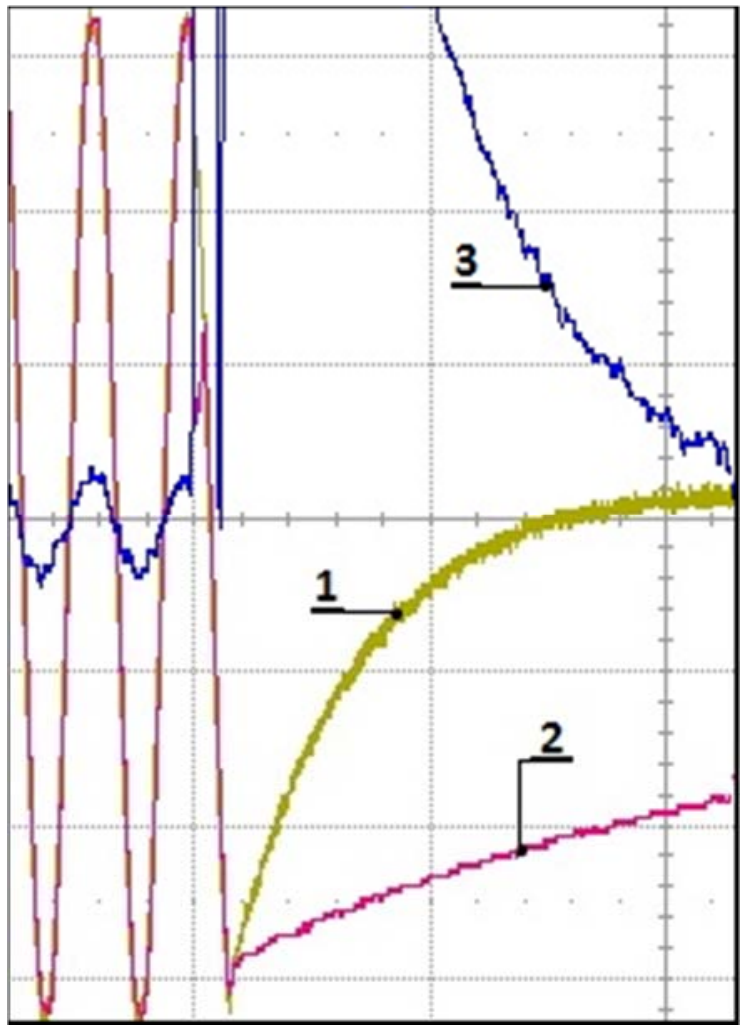

Fig 8 Short circuit of the PCB fuse. The fuse is working incorrectly, because it causes shut down of the circuit breaker. Curve 1 - voltage before PCB fuse, 2 - voltage after PCB fuse, 3 - current through the fuse. 


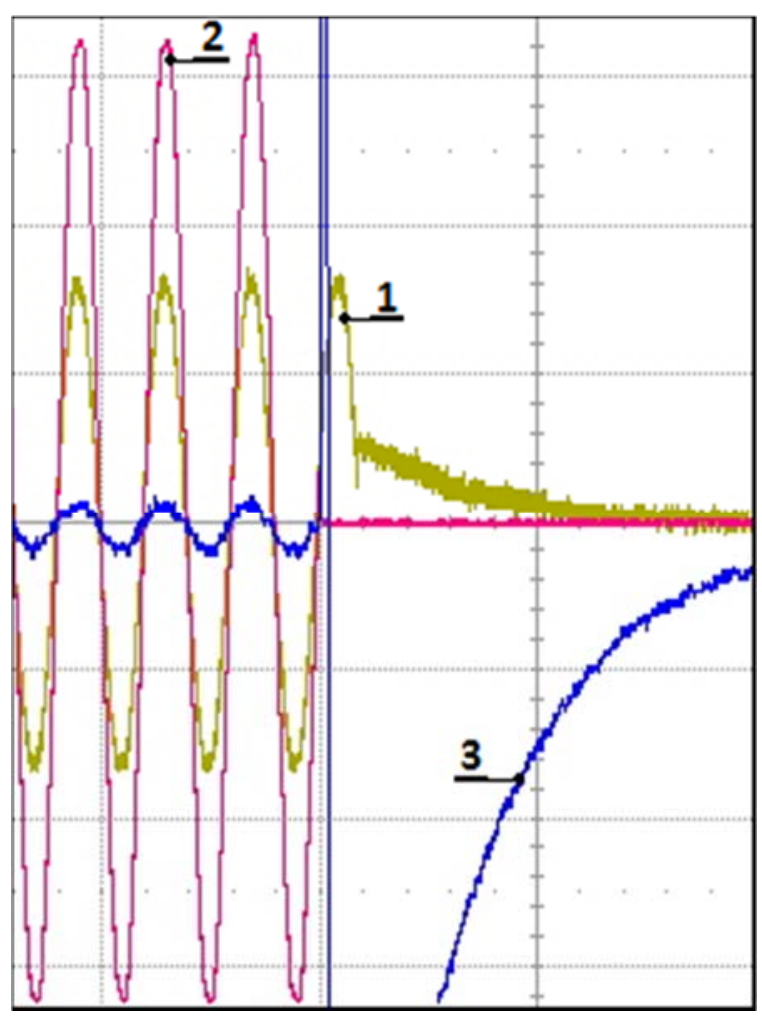

Fig. 9 Short circuit of the PCB fuse /first correction of the geometrical parameters/. Curve 1 - voltage before PCB fuse, 2 voltage after PCB fuse, 3 - current through the fuse.

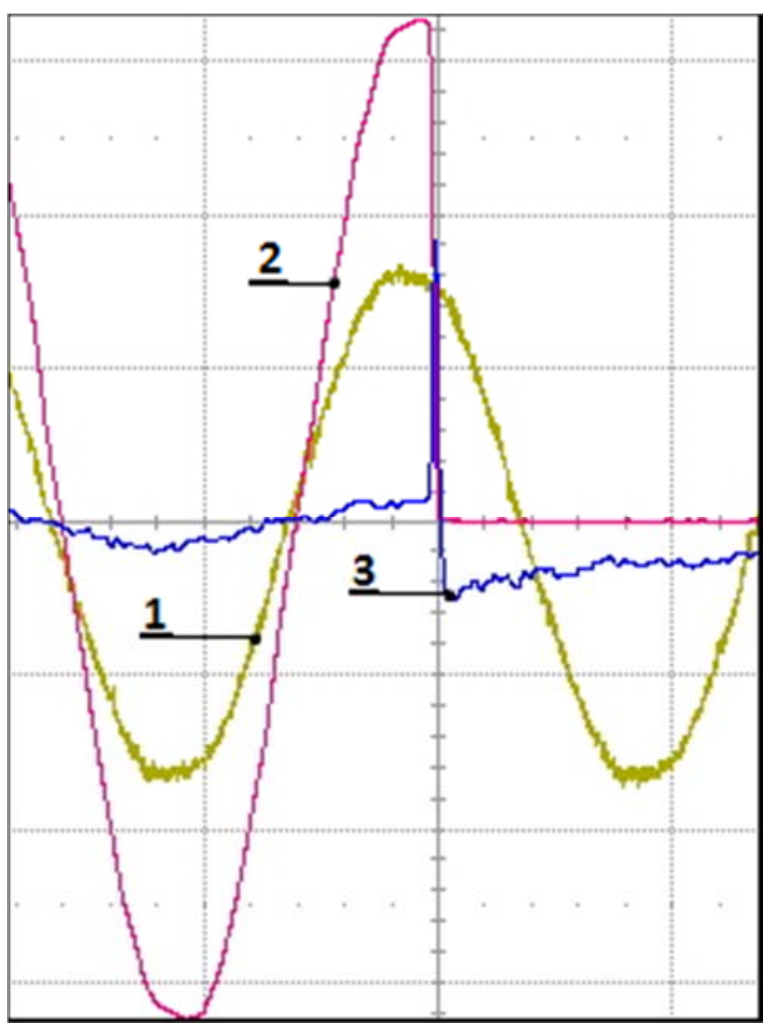

Fig. 10 Short circuit of the PCB fuse. The fuse is working correctly, because it does not cause shut down of the circuit breaker. Curve 1 - voltage before PCB fuse, 2 - voltage after PCB fuse, 3 - current through the fuse.

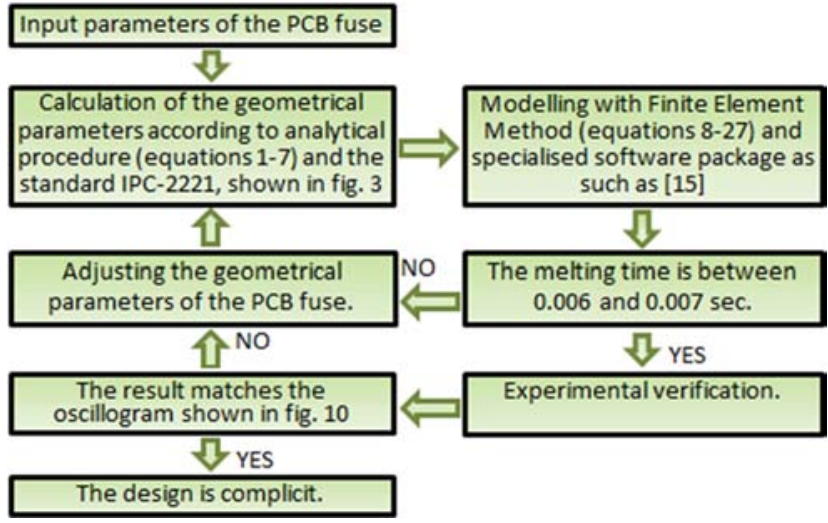

Fig. 11 The design procedure of PCB fuses based on FEM modeling and simulations.

\section{CONCLUSION}

Established design methodologies, based on analytical methods, are precise enough for fuses with a fusible plug, but they do not show the desirable precision for PCB fuses. This can cause the shutdown of the main supply circuit breaker, before the fuse under short circuit condition. The problem is seen even on switch mode power supplies available on the market.

The standard design procedure used for standard $\mathrm{PCB}$ track (Fig. 3, standard IPC-2221A) is not applicable for PCB fuses. Shoed modelling with FEM during the design procedure helps to improve and adapt the design of the PCB fuses.

Conducted experiments and models showed that the phase change time (Fig.7) can be taken as first assumption around $1 / 3$ of the $\mathrm{AC}$ period during the short circuit current. For $50 \mathrm{~Hz}$ input voltage that time is $0.006-0.007$ sec. In this conditions the designed PCB fuse can meet the requirements showed above and will work correctly (Fig. 10) as part of the entire installation (Fig. 1).

\section{ACKNOWLEDGMENTS}

This paper is developed in the frames of project "ELEVATE - ELEctrochemical Vehicle Advanced TEchnology", EP/M009394/1.

\section{REFERENCES}

[1] COONROD, J.: Keeping a Gauge on PCB Thermal Effects, High Frequency, pages 32-42; March 2014.

[2] GUOQUAN, R. - BEN, L. - DONGWEI, L. YINGQI, J.: Modal Analysis of the Printed Circuit Board on Finite Element Method. International Conference on Computer Science and Electronic Technology, ICCSET 2014, pp. 150 - 154, 2014.

[3] ADAM, J.: New Correlations Between Electrical Current and Temperature Rise in PCB Traces. Semiconductor Thermal Measurement and Management Symposium 2004. Twentieth Annual IEEE, 2004. 
[4] JOHANNES, A.: Thermal Management of Boards and Current-Carrying Capacity of Traces, Bodo's Power Systems, http://www.bodospower.com/ 2011, (actual on 12/06/2017).

[5] AMY, R. - AGLIETTI, G. - RICHARDSON, G.: Accuracy of simplified printed circuit board finite element models. Microelectronics Reliability 50, pp. 86-97. Elsevier. 2010.

[6] HAIYU, QI - GANESAN, S. - PECHT, M.: Nofault-found and intermittent failures in electronic products. Microelectronics Reliability 48, 663-674. Elsevier, 2008.

[7] LOHAN, J. - TIILIKKA, P. - RODGERS, P. FAGER, C. - RANTALA, J.: Using Experimental Analysis to Evaluate the Influence of Printed Circuit Board Construction on the Thermal Performance of Four Package Types in both Natural and Forced Convection. Seventh Intersociety Conference on Thermal and Thermomechanical Phenomena in Electronic Systems, May 23-26, 2000.

[8] LUNN, T.C.: Designing for Board level Electromagnetic Compatibility. Freescale Semiconductor application note NA2321, Rev. 1, 10/2005, 2005.

[9] Infineon Technologies, EMC and System-ESD Design Guidelines for Board Layout. Infineon application note AP24026, 2016 www.infineon.com (actual on 12/06/2017).

[10] BURKHARDT, A. - GREGG, C. - STANIFORTH, A.: Calculation of PCB Track Impedance. Polar instruments application note, Polar Instruments: https://www. polarinstruments.com/, 1999, (actual on 12/06/2017).

[11] BROOKS, D.: Temperature Rise in PCB Traces. UltraCad Desing Inc., Application note: www.UltraCAD.com , 1998, (actual on 12/06/2017)

[12] IPC-2221A Generic Standard on Printed Board Design IPC 2215 Sanders Road Northbrook, Illinois 60062-6135, May 2003.

[13] http://www.ultracad.com/, (actual on 12/06/2017).
[14] BROOKS, B. - ADAM, J.: Fusing Currents in Traces, http://www.ultracad.com/, UltraCad Desing Inc., Application note, 2015. (actual on 12/06/2017).

[15] http://comsol.com.

Received February 21, 2018, accepted April 27, 2018

\section{BIOGRAPHIES}

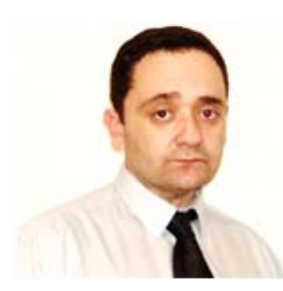

Borislav Dimitrov received the M.Sc and $\mathrm{PhD}$ degrees in Electrical Engineering from Technical University of Varna in 2000 and 2008, respectively. Currently he is working as a researcher at the University of Southampton, UK.

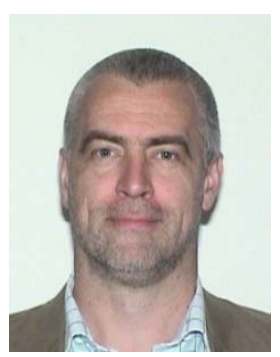

Andrew Cruden received the B.Eng. degree in electronic and electrical engineering, the M.Sc. degree in electrical power engineering, and the $\mathrm{Ph} . \mathrm{D}$. degree in the field of optical current sensing from the University of Strathclyde, Glasgow, U.K. In 2012 he became the Professor of Energy Technology at the University of Southampton, and is the Co-Director of the EPSRC CDT in Energy Storage and its Applications.

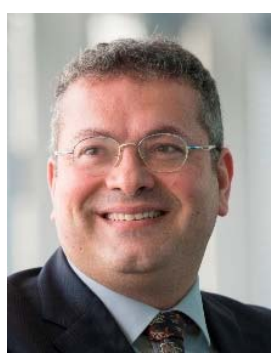

Suleiman M. Sharkh received the B.Eng. and Ph.D. degrees in electrical engineering from the University of Southampton, Southampton, U.K., in 1990 and 1994, respectively. He is Professor of Power Electronics, Machines and Drives, and Head of the Mechatronics Research Group at the University of Southampton. He is also the Managing Director of HiT Systems Ltd. He has published over 160 papers in academic journals and conferences. His main research interests are in the area of control, electrical machine and power electronics with applications to electric vehicles, marine propulsion, exhaust energy recovery and submersible pumps. 